qualidade na educação médica”, da OPS. O conjunto dessas propostas constitui-se no objeto de estudo da pesquisa realizada. Pelo estudo de cada uma das propostas, foram reconstruídos seus históricos, suas concepções teórico-metodológicas, seus processos de implantação e desenvolvimento. Pelas reconstruções e análises estruturais de cada uma, acumularam-se elementos que contribuem para a compreensão de cada uma delas, dos seus limites e possibilidades. Nas conclusões do estudo têm lugar algumas análises comparativas entre as propostas, enfoca-se o desenvolvimento das mesmas a partir de um enfoque independentecooperativo da saúde internacional e aprofunda-se nas contribuições que a proposta UNI, em estágio mais avançado de desenvolvimento, vêm trazendo para o esforço de construção de novos modelos acadêmicos. A análise das estratégias desenvolvidas pelas propostas e de seus processos de desenvolvimento não permitiram confirmar a hipótese inicial da pesquisa. Nesta, afirmava-se que a proposta UNI era a melhor concebida, estruturada $e$ portadora das estratégias mais potentes para o desenvolvimento de mudanças relevantes, duradouras e abrangentes na educação médica latino-americana. Apesar de ser a proposta que vem alcançando estágios de desenvolvimento mais avançados, verificou-se uma forte interação dela com as demais propostas e não foram identificados elementos suficientes para a confirmação, neste momento, da hipótese. As contribuições mais relevantes do estudo referem-se ao enfoque da educação médica como parte do setor saúde, a recuperação e registro de algumas das bases históricas do movimento latino-americano de educação médica $e$ a sistematização dos conteúdos, processos e resultados das propostas de mudança vigentes nos anos 90.

$$
\begin{array}{r}
\text { Marcio José de Almeida. } \\
\text { Tese de Doutorado, } 1997 \\
\text { Orientadora: Profa Dra Ana Maria Malik } \\
\text { Faculdade de Saúde Pública/USP. }
\end{array}
$$

\section{MEDICINA TECNOLÓGICA E PRÁTICA PROFISSIONAL CONTEMPORÂNEA: novos desafios, outros dilemas}

Estuda-se a profissão médica no Brasil, como exercício cotidiano de prática técnica $e$ realização de trabalho social produtor de serviços. Pesquisou-se como este trabalho, inserido no modelo geral da medicina tecnológica, encontra-se submetido a constantes tensões e conflitos entre necessidades técnicas e sociais, o que foi buscado através do exame da relação entre o médico e seu processo de trabalho. Com base em histórias da vida de trabalho de médicos, formados entre 1980 e 1985 e exercendo a profissão na cidade de São Paulo, foram gravadas entrevistas com clínicos, cirurgiões, pediatras e gineco-obstetras, no 
total de oito histórias. A análise do material deu-se no sentido do contraste histórico com pesquisa anterior relativa a médicos formados entre 1930-1955 e também da perspectiva de um exame aprofundado da medicina tecnológica atual. Observou-se uma ampliação do assalariamento e da perda da autonomia mercantil; uma intensificação de conflitos de base institucional acerca do controle da clientela e das condições de trabalho; e, ainda, uma maior complexidade técnica em razão da especialização e dos recursos instrumentais da intervenção. Caracterizou-se esta situação como existência de múltiplas engrenagens e meios tecnológicos, que passaram a ser intermediários na relação médico - trabalho. Novos desafios e dilemas são, então, detectados: o consultório-empresa e seu gerenciamento; o trabalho associativo e a convivência em coletivos e práticas parceiras; uma nova experiência de prática que lida com excessos de informações, de conhecimentos especializados, de técnicas armadas e de novas especialidades profissionais. $\mathrm{O}$ conjunto provoca uma mudança significativa das relações interindividuais e do sentido interativo de seus participantes, fazendo emergir uma ruptura crítica: a crise da confiança, situação emblemática da medicina tecnológica. Tal crise é examinada como questão técnica e questão ética do trabalho em medicina.

Lilia Blima Schraiber Tese de Livre-docência, 1997 Departamento de Medicina Preventiva/FMUSP 